\title{
APPLICABILITY OF RECYCLED PLASTIC FOR ROAD CONSTRUCTION IN SRI LANKA
}

\author{
DINUSHKA D.K.S. ${ }^{1}$, WAIDYASEKARA K.G.A.S. ${ }^{2} \&$ DEWAGODA K.G. ${ }^{3}$ \\ 1,2,3Department of Building Economics, University of Moratuwa, Moratuwa, Sri Lanka \\ ${ }^{1}$ senuradinushka@gmail.com, 2anuradha@uom.lk,3kaveesha.gihani.dewagoda@gmail.com
}

\begin{abstract}
Even though Polymer Modified Bitumen (PMB) is being emerged as an alternative for conventional asphalt in the global context, the use of recycled plastics to produce PMB is still an unorthodox concept in Sri Lanka. Therefore, the study aimed at evaluating the applicability of recycled plastic as a construction material in road construction in Sri Lanka. The study apprehended a qualitative approach comprising a literature review, followed by twelve expert interviews. The data were analysed using manual content analysis. The economic, environmental, and social benefits and enablers along with social, technology-related, knowledge-related, economic, and resource-related barriers in implementing PMB in Sri Lanka were identified. Additionally, strategies to overcome such barriers were suggested. The study further recommends the use of recycled polymers over virgin polymers; increasing the awareness level in the industry; extending the government involvement; and establishing a standard specification.
\end{abstract}

Keywords: Asphalt; Polymer Modified Bitumen (PMB); Recycled Plastic; Roads.

\section{Introduction}

Roads are built to improve the mobility of people and connectivity and are credited with important socio-economic improvements of a country (Demenge et al. 2015). In consideration of road construction, asphalt has been used widely as a binder for aggregate in road paving (Shafii et al. 2013). The common problem with all applications that involve asphalt materials is the temperature susceptibility, as asphalt tends to become brittle at low temperatures and soft at high temperatures (García-Travé et al. 2016). To overcome such issues and to reduce damages, polymer modified asphalt has been introduced so as to prolong the service life of road pavements even with the increment of traffic volume (Shafii et al. 2013). Use of polymers, which are either virgin or polymer waste, to modify the bitumen and to use as plastic-coated aggregates are being studied to improve the performance of the pavement (Rajasekaran et al. 2013).

Plastic, which is one type among various types of polymers, and a non-biodegradable material is said to be capable of remaining on earth for about 4500 years without degradation (Awaeed et al. 2015). Sri Lanka imports 160,000 metric tons of plastic raw materials and another 100,000 metric tons of finished and intermediate products every year and most of those remain in the environment as postconsumer plastics and polythene waste causing severe environmental and health problems (Gunarathna et al. 2010). On the other hand, Sri Lanka's road network density is among the highest in Asia, as the number of road kilometres per population exceeds the related indicators of both Pakistan and Bangladesh (Road Development Authority 2007). Khan et al. (2019) reported that recycling waste plastic has been an important strategy in order to reduce the amount of plastic and polythene waste accumulated in the environment thereby minimising the environmental threat encountered.

Even though Polymer Modified Bitumen (PMB) is being used for road construction globally, Sri Lanka's experience in PMB is limited due to lack of knowledge, technology, and quality issues (Sitinamaluwa and Mampearachchi 2014). However, roads as the dominant transport infrastructure in Sri Lanka, higher attention needs to be paid to develop the Sri Lankan road network using recycled polymer mixed bitumen mixtures. The purpose of this study is, therefore, to address the literature gap and the industrial requirement pertaining to such, by evaluating the applicability of recycled plastic as a material in road construction in the Sri Lankan context. Accordingly, the paper overviews the applicability of recycled polymers to modify asphalts in pavement construction in Sri Lankan context by identifying the suitable polymer types in road construction; identifying enablers and barriers and suggesting solutions to use polymer modified asphalt in pavement construction; and determining the impact of using polymers in road constructions in terms of sustainability pillars. 


\section{Literature Review}

\subsection{POLYMER MODIFIED BITUMEN (PMB) AS A CONSTRUCTION MATERIAL}

'Bitumen' is one of the oldest and widely used construction materials in civil engineering constructions (Hunter et al. 2015). Paying attention to environmental considerations, the use of alternative materials replacing traditional materials is to be incorporated in road construction (Balaguera et al. 2018). In addition, due to the restricted oil resources available to produce quality bitumen, lack of effective and functional control actions during the refinery process and the propulsion of getting the maximum economic benefits, the industry has been driven to concentrate on bitumen modification (Zhu and Kringos 2015). According to Becker et al. (2001), major reasons to modify bitumen with various typer of polymers are; to obtain softer blends at low service temperatures to reduce surface cracking; to obtain stiffer blends at much higher temperatures to reduce permanent deformation; to minimise viscosity of the mix at laying out temperatures at sites; to increase the stability and the strength of mixtures, fatigue resistance of blends, oxidation and aging resistance; to decrease structural thickness of pavements; and to decrease life cycle costs of pavements.

According to Kalantar et al. (2012), various studies have been published on the use of different types of waste polymers in road pavements, such as; Polyethylene Terephthalate (PET), Polyethylene (PE), Polyurethane (PU), Polypropylene (PP), Ethylene Vinyl Acetate (EVA), Styrene Butadiene Styrene (SBS), and Polyvinyl Chloride (PVC) etc. When it comes to the form of polymers to be used for the asphalt modifications, an interest is being emerged in using recycled polymers as the modification agent rather than virgin polymers (González et al. 2002). Since using newly formed polymers is expensive, either virgin polymer quantity that is used for modification has to be reduced or recycled polymers that show similar results in enhancing the properties in modified bitumen in comparison to virgin polymers have to be used (Kalantar et al. 2012).

\subsection{BENEFITS OF USING POLYMER MODIFIED BITUMEN (PMB)}

In an environmental point of view, use of recycled materials reduces the amount of plastic waste in new roads and maintenance of roads compared to virgin polymer resulting a major impact on environment (Leegwater et al. 2016). Another plus point of using recycled plastics to produce PMB is that waste plastics only melt but are not burnt during the production process, minimising the gas emissions, and diminishing the air pollution (Sangita and Kaur 2011). In an economic point of view, in terms of usage cost, achieving highest performance might not be the best option, but considering the cost effectiveness of technology and life cycle costs, society can achieve maximum benefits with comparatively higher performance of roads constructed using PMB (Zhu, B. et al. 2014). Using recycled polymers for $\mathrm{PMB}$ has much lower production cost compared to PMB made using virgin polymers (Leegwater et al. 2016). Bagui and Ghosh (2012) also argued that PMB is an economically and financially viable material. Similarly, in a cost analysis conducted by Souliman et al. (2016), they showed that PMB is 2.6 times cost-effective compared to conventional bitumen and that costeffectiveness increases with the increment of vehicle speed. Therefore, it is beneficial to use PMB from both environmental and economic points of view, considering the improvement of pavement performances and as a solution to the waste disposal (González et al. 2002). Other than the benefits of using PMB, challenges of using PMB also need to be assessed when it comes to implementing PMB.

\subsection{CHALLENGES OF USING POLYMER MODIFIED BITUMEN (PMB)}

Since properties of PMB change with the temperature, road designers need to determine the measures of performances, whether to use PMB or not and if yes, polymer quantity to be used in the roads must also be ascertained (Zhu et al. 2014). Further, the same study shows that PMB percentages to be used in asphalt mixes vary from one country to another due to the degree of traffic and climate conditions, as well as for a given 
country, it differs from one year to another. With respect to the Sri Lankan context, the study by Gunarathna et al. (2010) elaborated that plastic recycling industry has some constrains such as; limited number of wastewater treatment facilities; insufficient collection of plastics compared to the capacity of plastic recycling; lack of standard techniques in collecting and sorting plastics; complications in getting Environmental Protection License (EPL); and lack of suitable land around major cities to implement large scale plastic recycling plants, which ultimately leads to complications in implementing PMB constructions using recycled polymers in Sri Lanka.

Hence, the applicability of using PMB for road pavements in Sri Lanka needs to be assessed in terms of enablers, barriers and impacts of using PMB in the Sri Lankan context in order to provide solutions for industrial constraints of PMB implementation.

\section{3.o Research Method}

Creswell (2014) commended the qualitative approach, as it is the most suitable, if the existing literature is not extensive or if the variables to be explored are unknown. Besides, the study apprehended a qualitative approach as it would value and encourage the free flow of ideas, opinions, perceptions, and experience of people in order to develop this conceptual idea. Accordingly, twelve (12) face-to-face expert interviews of semi-structured design were conducted with professionals such as Engineering and Quantity Surveying professions, who are having more than 15 years of experience in road construction in Sri Lanka. Literature findings were solely related to the developed and developing countries of Europe and Asia. Hence, one of the objectives of the expert interviews was to appraise the applicability of recycled plastic in Sri Lankan road construction. When observing the road construction industry, using PMB is a novel measure in the Sri Lankan context. Therefore, another objective was to evaluate the establishment of the PMB technology to Sri Lanka through the experience and the knowledge of the interviewees. The profile of the interviewees is presented in Table 1.

Table 1: Profile of Interviewees

\begin{tabular}{|c|c|c|c|}
\hline $\begin{array}{c}\text { Interviewee } \\
\text { Code }\end{array}$ & Profession & Designation & Experience \\
\hline IE1 & Engineer & Senior Project Engineer & 24 years \\
\hline IE2 & Engineer & Senior Project Engineer & 17 years \\
\hline IE3 & Engineer & Chief Engineer & 24 years \\
\hline IE4 & Engineer & Project Director & 22 years \\
\hline IE5 & Engineer & Senior Project Engineer & 20 years \\
\hline IE6 & Engineer & Senior Project Engineer & 20 years \\
\hline IE7 & Engineer & Senior Project Engineer & 15 years \\
\hline IE8 & Engineer & Senior Project Engineer & 15 years \\
\hline IE9 & $\begin{array}{l}\text { Quantity } \\
\text { Surveyor }\end{array}$ & Senior Quantity Surveyor & 15 years \\
\hline IE10 & $\begin{array}{l}\text { Quantity } \\
\text { Surveyor }\end{array}$ & $\begin{array}{l}\text { Manager Contract } \\
\text { Administrator }\end{array}$ & 20 years \\
\hline IE11 & $\begin{array}{l}\text { Quantity } \\
\text { Surveyor }\end{array}$ & Quantity Surveyor & 14 years \\
\hline IE12 & $\begin{array}{l}\text { Quantity } \\
\text { Surveyor }\end{array}$ & Senior Quantity Surveyor & 15 years \\
\hline
\end{tabular}

The interviewees were selected using purposive sampling, in consideration of their knowledge of and experience in road construction in Sri Lanka, their insight and exposure in establishing new and innovative concepts related to road construction, their willingness and availability for interviewing (Etikan et al. 2016). Data were analysed manually using content analysis as it is based on 
interpretations, explanations and clarifications that are obtainable from the collected data where there are no quantitative representations of the data (Boughzala et al., 2012).

\subsection{Research Findings and Analysis}

\subsection{APPLICATION OF POLYMER MODIFIED BITUMEN (PMB) IN THE SRI LANKAN CONTEXT}

Upon reviewing the importance of using $\mathrm{PMB}$, it was revealed that as the porous technology is being used for most of the national and provincial roads in present, combining porous technology with PMB will be an upgrade compared to the conventional roads. Besides, being a partial solution for the environmental pollution by waste plastics, interviewees suggested that PMB will be a partial solution for the scarcity of construction materials that are used for conventional asphalt pavement constructions, specially bitumen. Another important fact highlighted by the interviewees was the increment of the durability of asphalt pavements by adding polymers. It makes a direct and indirect impact on the operational stage of the roads socially and economically. Such an enhancement would affect the qualitative factors concerning the economic dimension including, but not limited to a reduction of maintenance frequency, thereby minimising the maintenance cost. In the social dimension, the community would be benefitted by time savings due to reduced traffic, comfortable rides, etc.

Among the two polymer types that can be used to modify asphalts: virgin polymers and recycled polymers, interviewees suggested using recycled polymer to produce polymer modified asphalts over virgin polymers. The rationale of the suggestion is that recycled polymers provide a partial solution to the waste plastic problem and the scarcity of pavement construction materials in Sri Lanka. However, several interviewees argued that the inability to achieve the same purity level as virgin polymers through recycled polymers, not having a properly established waste plastic process within the country and the non-availability of waste plastics in required bulk quantities as several drawbacks in using recycled polymers over virgin polymers.

Considering the available waste plastic quantities and the types of waste plastics, a majority of the interviewees suggested to use PET, Low Density Polyethylene (LDPE) and High Density Polyethylene (HDPE) for the polymer modification of asphalts in Sri Lanka. However, proper testing and sampling is essential in using such polymer types. From both literature review and expert interviews, it was found that the use of PMB would improve the rutting resistance, fatigue resistance and stiffness of the pavement compared to conventional asphalts. Additionally, as per the interviewees, increment in bonding and flexibility of bonded particles will improve the responsiveness to the temperature and the surface irregularities resulting in a higher International Roughness Index (IRI) value.

Further, majority of interviewees highlighted that, there are no publications for identification, specification, and any assessment criterion for the application of PMB in Sri Lanka. Therefore, it was identified as an area to be improved since performance evaluation tests are needed for the purpose of establishing standards and specifications and to follow those standard. Literature findings on the performance evaluation tests for asphalt pavement construction were presented to the interviewees, who asserted that all the test methods identified through literature are available in Sri Lanka and that all the tests to be conducted for PMB are same as the conventional asphalts in Sri Lanka. Those performance evaluation tests are; Marshall Stability test, Softening point test, Penetration Index test, Flash point test, Fire point test, Viscosity test, Ductility Index test, Aggregated Impact Value test, Soundness test, Void Measurement test, Moisture Absorption test, and Los Angel's Abrasion Test.

4.2 BARRIERS IN IMPLEMENTING POLYMER MODIFIED BITUMEN (PMB) AND RESPECTIVE STRATEGIES TO OVERCOME THE BARRIERS

Barriers to implement PMB in Sri Lanka were presented under the main five (5) categories namely; 
social, technological, knowledge-related, economic, and resource-related barriers. The barriers found under each category are elaborated in Table 2.

Table 2: Barriers in implementing polymer modified asphalt technology in Sri Lanka

\begin{tabular}{|c|c|}
\hline Barrier Category & Barriers \\
\hline Social Barriers & $\begin{array}{ll}\text { - } & \text { Less awareness on PMB in Sri Lanka } \\
\text { - } & \text { Resistance to change from existing technologies }\end{array}$ \\
\hline Technology-Related Barriers & $\begin{array}{l}\text { - Resistance to make changes in plant and equipment } \\
\text { - Limited number of pilot projects }\end{array}$ \\
\hline Knowledge-Related Barriers & $\begin{array}{l}\text { - Limited researches on using polymer PMB in Sri Lanka } \\
\text { - Non-availability of specifications for PMB in Sri Lanka }\end{array}$ \\
\hline Economic Barriers & $\begin{array}{l}\text { - Less involvement of government sector } \\
\text { - Risks of using experimental materials }\end{array}$ \\
\hline Resources-Related Barriers & $\begin{array}{l}\text { - Less availability of polymer types } \\
\text { - } \quad \text { Lower purity level of recycled polymers }\end{array}$ \\
\hline
\end{tabular}

Sitinamaluwa and Mampearachchi (2014) stated that lack of knowledge, technology and qualityrelated problems are the main barriers in implementing polymer modification of asphalts in Sri Lanka. According to the interviewees, lack of awareness on PMB technology is the main barrier for implementation in Sri Lanka. Even though this technology is upward trending other countries, the awareness of the Sri Lankan construction industry is low-lying. Besides, having no practical experiments to study the behaviours and the properties of the polymer modified pavements is another technology-related barrier, which narrows the possibilities for conducting further researches and analyses. Furthermore, as emphasised by many interviewees, the lack of recognition of application of PMB in the road industry may cause many financial problems to both RDA and contractors until the advantages or benefits over conventional asphalts in Sri Lanka are realised. On the other hand, applicability of quality-related tests concerning the reliability of suggested methods might raise doubts at the beginning with the results of applications. Interviewees further argued that less confidence level on adapting to a new technology is causing due to the human nature of less willingness to move past the current technologies. Interviewees further explained it as a cultural aspect, which is a quantifiable effect, but adversely directly impacting decision making relating to the road construction.

In order to overcome such barriers, strategies such as; increasing the awareness level through conference proceedings, workshops, Continuing Professional Development (CPD) programs etc.; involvement of the government bodies; getting foreign expertise; and conducting theoretical and experimental researches were suggested by the interviewees for the implementation of polymer modified asphalt in Sri Lanka. In addition, carrying out technical surveys on PMB would increase the awareness level besides awareness programs, workshops, and seminars. Accordingly, increasing the awareness level would open up the possibilities to resolve technical related problems and most importantly it would help the industry to understand the benefits and the advantages of the technology within road construction industry and as well, the environment. Interviewees also suggested obtaining foreign expertise, who have experience with the asphalt modification with polymer, in order to conduct awareness programs to the industry professionals and also to consult on researches and on road projects as some strategies to overcome such barriers.

\subsection{ENABLERS IN IMPLEMENTING POLYMER MODIFIED BITUMEN (PMB)}

According to the expert interview findings, the two major enablers to implement PMB in Sri Lanka are, availability of waste plastics to explore various polymer types to modify asphalt; and the ability to get required consultations from other countries. Even though PMB constructions are at the elementary stage in Sri Lanka in terms of implementation so far, as a result of the effective 
relationships with the construction industries of other countries, opportunities have been open up to study on the technical requirements referring to their PMB projects. For an instance, since India is having the same climatic conditions and the applications of the PMB projects, analyses of their data will help to decide whether PMB technology is beneficial to carry out in Sri Lanka and to go through the implementation process. Additionally, it was highlighted that the availability of the number of polymer types to explore this polymer modification technology in Sri Lanka as an enabler to implement polymer modification of asphalts. Not having an impactful approach to resolve the environmental waste plastic issue so far is another incentive to implement PMB technology in Sri Lanka. Accordingly, as highlighted by the interviewees, analysing the available data and cost-benefit analyses from the other countries will help to realise the value of the implementation of PMB technology in Sri Lanka.

\subsection{IMPACT OF USING PMB IN ROAD CONSTRUCTION IN SRI LANKA}

Impact of using polymers for road construction was deduced via expert interviews based on the three pillars of sustainability and the expected status of PMB compared to conventional asphalts in Sri Lanka. Accordingly, adding polymers to the asphalt modification might escalate the initial cost depending on the level of the exposure to the asphalt modification technology, and due to the cost difference between polymer and replaceable aggregate and bitumen quantities with polymer. Nevertheless, improvement of properties of PMB will decrease the maintenance frequencies, which ultimately impact the reduction of operational costs of the roads, further resulting in the reduction of life cycle cost of the roads compared to conventional asphalts. Accordingly, it is evident that PMB based on recycled plastics facilitates long term value-creation contributing to economic sustainability. Additionally, without importing virgin polymers from other countries, the use of waste plastics would not be economical at the earlier stages of implementing PMB in Sri Lanka. However, with the adaption and evolvement of the government in using PMB, it would enhance the economic sustainability.

One option of the interviewees was to add polymers to bitumen replacing a percentage of the total bitumen volume. Another way was replacing the percentage weightage of aggregate with polymer coated granules. Either way, it is reducing the raw material content of the asphalt mixture compared to conventional asphalt mixture, providing a replacement of raw materials, which gives a positive impact on the environmental sustainability. Even if the replaceable percentage of bitumen is a smaller value, considering the Sri Lankan road construction industry and its volume of work per annum, replaceable quantity becomes larger in each year. According to the opinions of the interviewees, if the recycling processes were done keeping its required purity level of the polymers and with the work volume of road contraction per year, the use of PMB for the pavement construction in Sri Lanka would be highly sustainable. Improvement of the irregularities of the pavement surface will reduce the depreciation of the vehicles. Besides, with the increment in the lifetime of pavements and with the improvements of the properties, the number of rehabilitation and maintenance activities on the road pavements will reduce resulting less vehicular traffic on roads saving the travelling time and associated costs. On the other hand, with the involvement of many government sectors such as RDA, Central Environmental Authority (CEA), municipal councils to co-operate with the PMB concept, it will open up many social opportunities and the possibilities.

Moreover, as emphasised by many interviewees, with the establishment of PMB, the purity level of the recycled polymers has to be maintained at a higher level. For the purpose, waste plastic recycling within the country has to achieve a certain level of quality and it needs to be done according to a wellestablished process from the stage of waste plastic collection. This would facilitate in increasing the effectiveness of waste management in Sri Lanka creating many job opportunities. Furthermore, considering the expected exposure to PMB technology in Sri Lanka, the status of the PMB compared to conventional asphalts was analysed based on time, cost and quality parameters. Accordingly, the 
study revealed that even though PMB has no noticeable impact on the construction time, substantial quality improvements along with considerable savings in construction cost could be achieved in comparison to conventional asphalts. Further, interviewees emphasised the need of revising the existing SCA/5: Standard Specifications for Construction and Maintenance of Roads and Bridges or publishing a separate specification for PMB road pavement constructions in Sri Lanka.

\subsection{Conclusions and Recommendations}

Asphalt being the main composite material used for the road pavement construction and with the rise of traffic load on road pavements, many shortcomings were observed, and many researchers were keen on finding solutions to overcome those shortcomings. Even though many studies were done to overcome the distresses of conventional asphalt by polymer modification in other countries, the awareness level of using polymers to improve the asphalt properties is at a minimum level in Sri Lanka. Thus, this study makes the reader aware of the gap between the exposures of the countries that use PMB and the awareness level of Sri Lanka regarding the use of PMB. The study therefore makes a useful theoretical contribution by analysing the applicability of recycled plastic as a construction material in road construction in Sri Lanka.

The findings of this study put forward PMB as a notable and experimental concept to the Sri Lankan road construction industry and the community. Thus, opportunities derived from the PMB concept can be used for the development of environmental, economic, and socio-cultural aspects in developing countries such as Sri Lanka. During the research process, limited availability of projects, which are in the testing mode, less awareness on the concept of using polymer for asphalt modification, less availability of the professionals who has both conceptual knowledge and experience on the PMB in the Sri Lankan road construction industry were the major limitations encountered. Most significantly, limited availability of the PMB used projects was a major limitation since those projects are in testing mode and 'restricted' on publishing records publicly by the authorities until the tests are completed.

It is further recommended to take necessary steps to increase the awareness of the use of polymer modified asphalt in road pavements in the Sri Lankan road construction industry. For such arrangements, involvement of the government authorities would make a considerable boost in terms of awareness level within the construction industry and the society. Additionally, approaching from the employer's standpoint rather than the contractor's standpoint is recommended to implement the PMB technology in Sri Lanka, in order to keep the competitiveness in the procurement processes. Moreover, as discussed in the study, it is recommended to fulfil the gap of establishing standard specifications for polymer modified asphalt through a revision to SCA/5: Standard Specifications for Construction and Maintenance of Roads and Bridges or publicising a separate specification for road pavement constructions in Sri Lanka.

\section{6.o References}

Alzuhairi M. Al-Ghaban A., Almutalabi S. 2016. Chemical Recycling of Polyethylene Terephthalate (PET) as Additive for Asphalt. J. Pure Appl. Sci., 28(2): 675-679.

Awaeed K.M., Fahad B.M., Rasool D.A. 2015. Utilization of Waste Plastic Water Bottle as a Modifier For Asphalt mixture Properties. J. Eng. Dev., 2O(2): 1813-7822.

Awwad M. and Shbeeb L. 2007. The use of Polyethylene in hot asphalt mixures. Am. J. Appl. Sci., 4(6): 390-396.

Bagui S. Ghosh A. 2012. Economic and Financial Analysis for Polymer Modified Bitumen. Malaysian J. Civ. Eng., 24(1): 96106.

Balaguera A., Carvajal G.I., Alberti J., Fullana-Palmer P. 2018. Life cycle assessment of road construction alternative materials: A literature review. Resour. Conserv. Recycl., 132 : 37-48. https://doi.org/10.1016/j.resconrec.2018.01.003

Bale A. 2011. Potential Reuse Of Plastic Waste In Road. Int. J. Adv. Eng. Technol., 2(3): 233-236.

Boughzala Y., Moscarola J., Bouzid I. 2012. Comparison of Sphinx Lexica and decision explorer. Cognitive maps, content analysis and lexical statics.

Becker Y., Méndez M., Rodríguez Y. 2001. Polymer Modified Asphalt. Vision Tecnologica, 9. 
Creswell J. 2014. Research design : qualitative, quantitative, and mixed methods approaches. 4th ed. California: SAGE Publications, Inc..

Demenge J., Alba R., Welle K., Addisu A., Manjur K., Mehta, A., Woldearegay K. 2015. Multifunctional roads: the potential effects of combined roads and water harvesting infrastructure on livelihoods and poverty in Ethiopia. J. Infrastruct. Dev., $7(2)$.

Etikan I., Musa S.A., Alkassim RS. 2016. Comparison of convenience sampling and purposive sampling. Am. J. Theor. App. Stat. 5(1): 1-4.

García-Travé G., Tauste R., Moreno-Navarro F., Sol-Sánchez M., Rubio-Gámez M. 2016. Use of Reclaimed Geomembranes for Modification of Mechanical Performance of Bituminous Binders. J. Mater. Civ. Eng., 28(7).

González O., Peña J., Muñoz M., Santamaría A., Pérez-Lepe A., Martínez-Boza F., Gallegos C. 2002. Rheological Techniques as a Tool To Analyze Polymer-Bitumen Interactions: Bitumen Modified with Polyethylene and Polyethylene-Based Blends. Energy Fuels, 16(5): 1256-1263.

Gunarathna G., Bandara N., Liyanage S. 2010. Analysis of Issues and Constraints Associated With Plastic Recycling Industry in Sri Lanka. Nugegoda, Sri Lanka, Department of Forestry and Environmental Science, University of Sri Jayewardenepura, Sri Lanka. http://journals.sjp.ac.lk/index.php/fesympo/article/viewFile/168/75

Hunter D.R., Self A., Read PJ. 2015. The Shell Bitumen Handbook. Sixth edition ed. Westminster: ICE Publishing.

Jafar J. 2015. Utilisation of Waste Plastic in Bituminous Mix for Improved Performance of Roads. KSCE J. Civ. Eng., 1-7. https://doi.org/10.1007/s12205-015-0511-0

Kalantar Z., Karim M., Mahrez A. 2012. A review of using waste and virgin polymer in pavement. Constr. Build. Mater., 33: 55-62. https://doi.org/10.1016/j.conbuildmat.2012.01.009

Khan F., Ahmed W., Najmi A. 2019. Understanding consumers' behavior intentions towards dealing with the plastic waste: Perspective of a developing country. Resour. Conserv. Recycl., 142: 49-58.

Kinigama G. 2011. Development of methodology to estimate esal values for low volume roads in provincial sector, Moratuwa: University of Moratuwa.

Kofteci S., Ahamedzade P. and Kultayev B. 2014. Performance evaluation of bitumen modified by various types of waste plastics. Constr. Build. Mater., 73(1): 592-602.

Leegwater G., Komacka J., Liu G., Nielsen E., Remisova E. 2016. Technical Performance and Benefits of Recycling of Reclaimed Asphalt Containing Polymer-modified Binder in Premium Surface Layers. In: Mater. Infrastruct.. New Jersey: John Wiley \& Sons, pp. 19-32.

Punch K. 2014. Introduction to Social Research: Quantitative and Qualitative Approaches. 3rd ed. Thousand Oaks: Sage publications.

Rajasekaran S., Vasudevan R. and Paulraj S. 2013. Reuse of Waste Plastics Coated Aggregates-Bitumen Mix Composite For Road Application - Green Method. Am. J. Eng. Res. (AJER), 2(11): 01-13.

Road Development Authority. 2007. National Road Master Plan (2007 - 2017), Baththaramulla, Sri Lanka: Road Development Authority.

Sangita G., Kaur V. 2011. A Novel Approach to Improve Road Quality by Utilizing Plastic Waste in Road Construction. J. Environ. Res. Dev., 5(4): 1036-1042.

Saunders B., Sim J., Kingstone T., Baker S., Waterfield J., Bartlam B., Burroughs H., Jinks C. 2018. Saturation in qualitative research: Exploring its conceptualization and operationalization. Qual. Quantity. 52(4): 1893-1907.

Shafii M.A., Ahmad J., Shaffie E. 2013. Physical properties of asphalt emulsion modified with natural rubber latex. World J. Eng., 10(2): 159-164.

Sitinamaluwa H., and Mampearachchi W. 2014. Development of a polymer-modified bitumen specification based on empirical tests - case study for Sri Lanka. Road Mater. Pavement Des., 15(3): 712-720.

Souliman M., Mamlouk M., Eifert A. 2016. Cost-effectiveness of Rubber and Polymer Modified Asphalt Mixtures as Related to Sustainable Fatigue Performance. Procedia Eng., 145: 404-411. https://doi.org/10.1016/j.proeng.2016.04.007

Subei, N., Saxena S.K., Mohammadi J. 1991. A BEM-FEM Approach for Analysis of Distresses in Pavements. Int. J. Numer. Anal. Methods Geomech., 15: 103-119.

Zhu J., Birgisson B., Kringos N. 2014. Polymer modification of bitumen: Advances and challenges. Eur. Polym. J., 54: 18-38.

Zhu J., Kringos N. 2015. Towards the development of a viscoelastic model for phase separation in polymer-modified bitumen. Road Mater. Pavement Des., 16: 39-49. 